\title{
Written self-management plans improve asthma control
}

\author{
RL Cowie MD
}

$\mathrm{P}$ atient participation is necessary for the treatment of any chronic disease but particularly for diseases that run a variable course. The day-to-day variability of asthma demands careful participation by the individual with the disease and his or her caregivers if they are to achieve optimal control and enjoy a normal lifestyle (1).

Most, if not all, asthma guidelines emphasize that patient education is as important as the prescription of appropriate medication (1). Indeed, the prescription and the education are inseparable. Without instruction in the use of inhaler devices, without the knowledge of what constitutes disease control, and without the understanding of the role of medical and nonmedical interventions, it is not likely that asthma control will be achieved, even when all of the relevant medications have been prescribed. Patient education in a variable disease must also include some component of disease monitoring linked with a self-management plan. Probably the most important aspect of patient education toward self-management is preventing the development of severe and potentially life-threatening exacerbations (2). Unfortunately, it has been shown that even those patients who have a good knowledge of their disease may not apply this knowledge to the management of an exacerbation of their asthma (3). The appropriate use of self-management plans in asthma thus requires careful education with the emphasis on changing behaviour (rather than the acquisition of knowledge). Action plans are not suitable for all patients with asthma (4) and are most effective in those with more severe disease (5).

It is often difficult to provide an evidence base for an intervention, such as asthma self-management, that requires people to change their behaviour. This difficulty is demonstrated by the conflicting conclusions of two recent Cochrane reviews of this topic $(6,7)$. The former review concluded that the inclusion of a written action plan in an education program for asthma improved health outcomes (6). The latter review of an almost identical selection of studies concluded that only six published studies were valid and that there was insufficient evidence to support the value of action plans (7). In fact, only one of the cited studies examined the impact of an action plan versus no action plan (8); the other five studies compared different types of plans, or an education program and an action plan with no education or plan (7). Even one of the most recent studies failed to examine self-management plans on an even playing field, although it did suggest, as may be expected, that a plan without appropriate education is unlikely to result in a change in behaviour (9).

The lack of evidence to support the role of action plans in patient management of asthma should not be seen as evidence of lack of efficacy. We know that it is very difficult to change behaviour, but that difficulty should not stop us from instructing our patients to manage their asthma any more than it should stop us from offering advice on smoking cessation or other difficult interventions that require behavioural change.

Notwithstanding the admittedly incomplete evidence, it is difficult to avoid the conclusion that written action plans should be part of the management of asthma in patients, especially in those who suffer from severe exacerbations $(5,8)$ and who are ready to make behavioural changes $(10,11)$.

\section{REFERENCES}

1. Boulet LP, Becker A, Berube D, Beveridge R, Ernst P. Canadian Asthma Consensus Report, 1999. Canadian Asthma Consensus Group. CMAJ 1999;161(Suppl 11):S1-61.

2. Kolbe J, Fergusson W, Vamos M, et al. Case-control study of severe life threatening asthma (SLTA) in adults: demographics, health care, and management of the acute attack. Thorax 1997;55:1007-15.

3. Kolbe J, Vamos M, James F, et al. Assessment of practical knowledge of self-management of acute asthma. Chest 1996;109:86-90.

4. Adams RJ, Smith BJ, Ruffin RE. Patient preferences for autonomy in decision making in asthma management. Thorax 2001;56:126-32.

5. Lopez-Vina A, del Castillo-Arevalo E. Influence of peak expiratory flow monitoring on an asthma self-management education programme. Respir Med 2000;94:760-6.

6. Gibson PG, Coughlan J, Wilson AJ, et al. Self-management education and regular practitioner review for adults with asthma. Cochrane Database Syst Rev 2000;2:CD001117.

7. Toelle BG, Ram FSF. Written individualised management plans for asthma in children and adults. Cochrane Database Syst Rev 2002;3:CD002171.

8. Cowie RL, Revitt RG, Underwood MF, et al. The effect of a peak flow-based action plan in the prevention of exacerbations of asthma. Chest 1997;112:1534-8.

9. Cote J, Bowie D, Robichaud P, Parent JG, Battisti L, Boulet LP. Evaluation of two different educational interventions for adult patients consulting with an acute asthma exacerbation. Am J Respir Crit Care Med 2002;163:1415-9.

10. Green LW, Frankish CJ. Theories and principles of health education applied to asthma. Chest 1994;106(Suppl):219S-30S.

11. Prochaska JO, DiClemente CC, Velicer WF, et al. Predicting change in smoking status for self-changers. Addict Behav $1985 ; 10: 395-406$. 


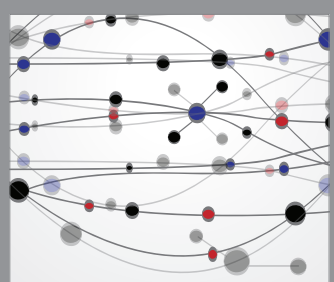

The Scientific World Journal
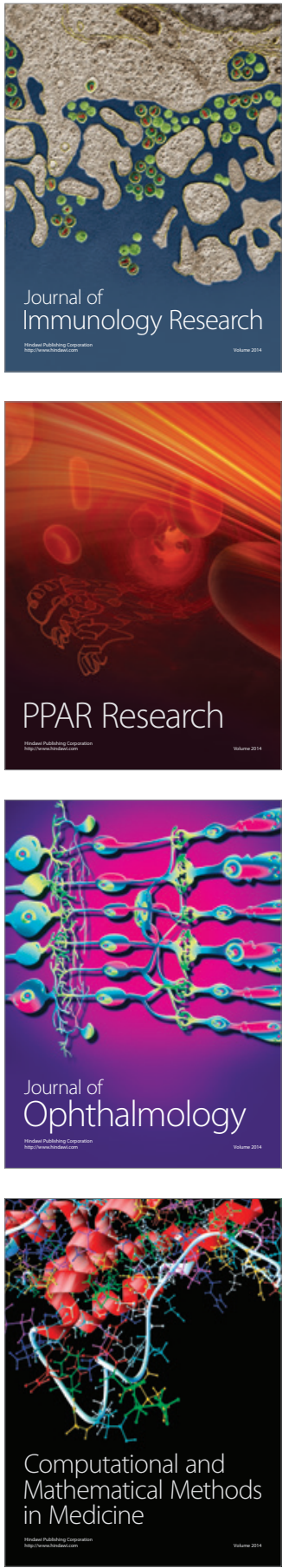

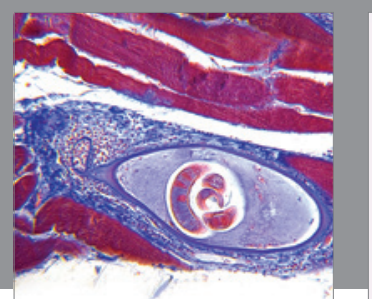

Gastroenterology Research and Practice

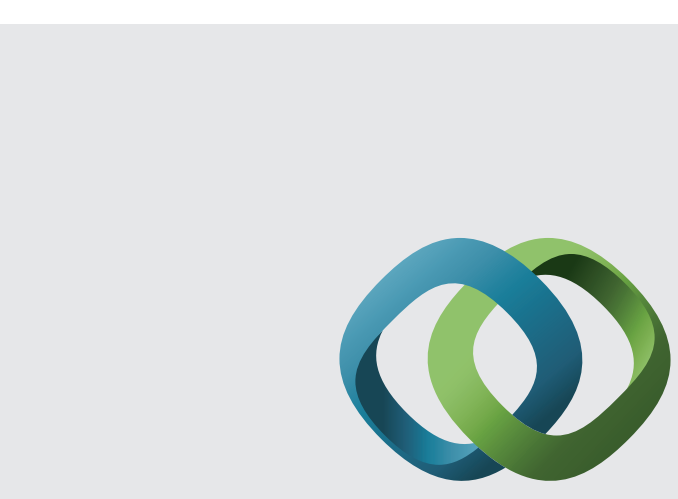

\section{Hindawi}

Submit your manuscripts at

http://www.hindawi.com
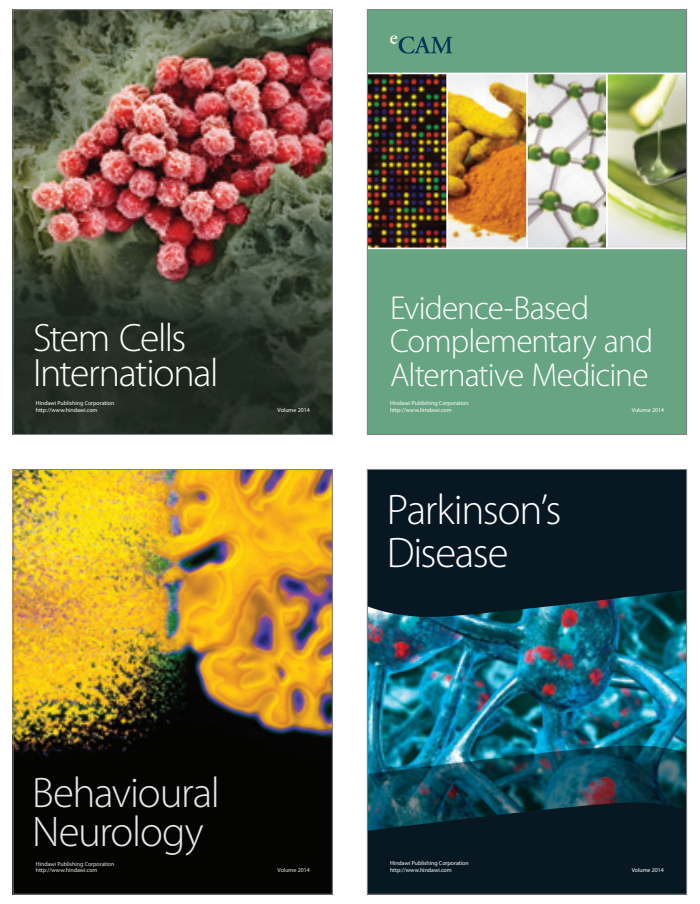
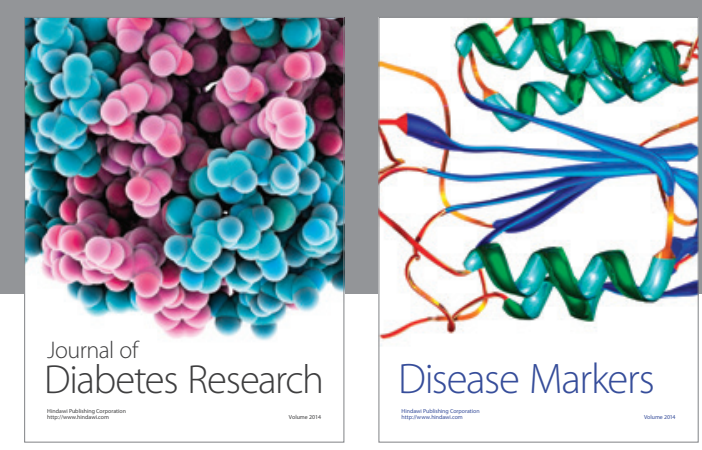

Disease Markers
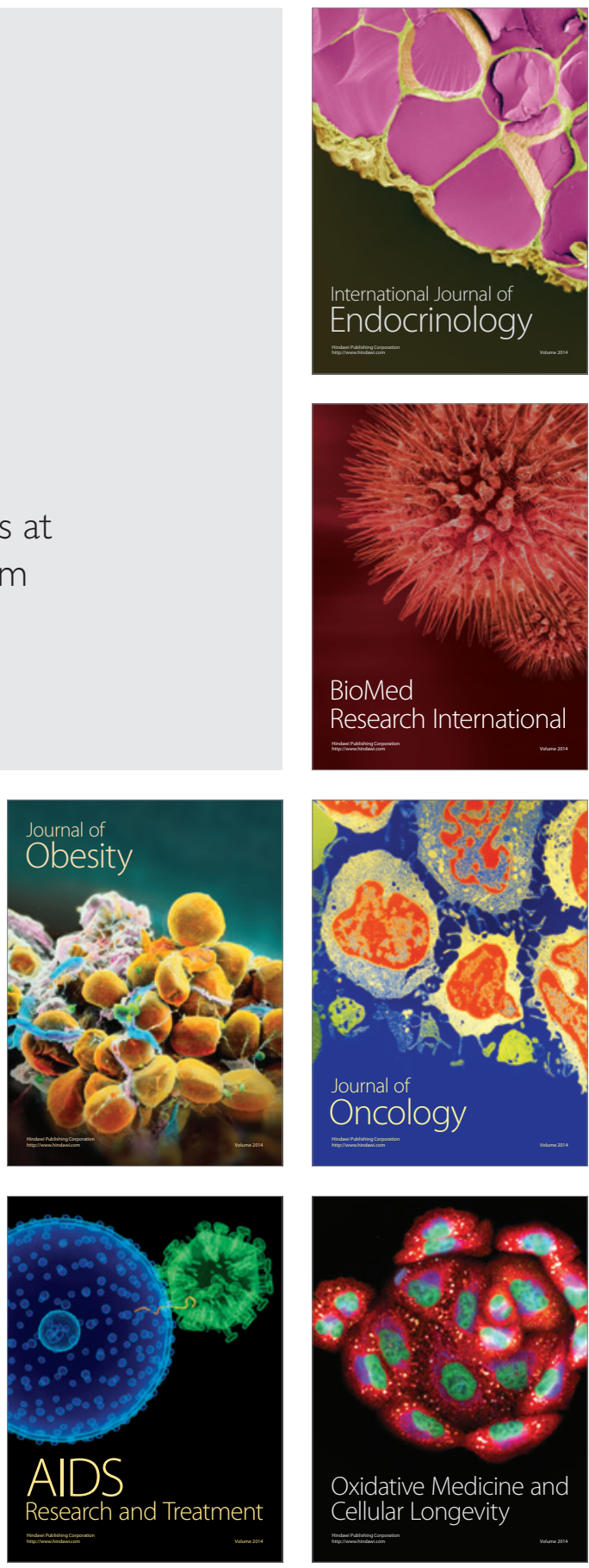